\title{
High Prevalence of Esophageal Acid Exposure in Very Low Birth Weight Infants Presenting or Not Bronchopulmonary Dysplasia: A Prospective Cross-Sectional Study
}

\author{
Thaís Mendes-Lopes ${ }^{1}$, José Dirceu Ribeiro² and Maria Aparecida Mezzacappa ${ }^{3 *}$ \\ ${ }^{1}$ Child and Adolescent Healthcare Program, University ofCampinas School of Medicine-UNICAMP, Campinas/São Paulo/Brazil \\ ${ }^{2}$ Department of Pediatrics, University of Campinas School of Medicine-UNICAMP, Campinas/São Paulo/Brazil \\ ${ }^{3}$ Division of Neonatology, Department of Pediatrics, University of Campinas School of Medicine-UNICAMP,Campinas/São Paulo/Brazil
}

\section{Abstract}

Background: A high frequency of treatment for gastroesophageal reflux disease is observed in neonates with Bronchopulmonary Dysplasia (BPD). The association between these illnesses is controversial.

Objective: To determine the prevalence of reflux index $\geq 10 \%$, in very low birth weight infants, presenting or not $\mathrm{BPD}$, using esophageal $\mathrm{pH}$ monitoring.

Methods: A prospective cross-sectional study was conducted. Thirty-five newborns presenting BPD and 15 newborns not presenting BPD underwent distal esophageal $\mathrm{pH}$ monitoring during their stay in a university hospital neonatal unit. The frequency of symptoms and gastroesophageal reflux treatment was studied in both groups.

Results: The prevalence of reflux index $\geq 10 \%$ did not differ between groups presenting $(65.7 \%)$ and not presenting BPD (93.3\%); $p=0.075$. Symptoms attributable to gastroesophageal reflux occurred in $91.4 \%$ of newborns presenting BPD and in $73.3 \%$ of the group not presenting BPD. Antireflux treatment was introduced to $80 \%$ of the subjects presenting BPD and to $20 \%$ of patients who were not presenting BPD; $(p<0.001)$.

Conclusions:There is a high prevalence of increased esophageal mucosal exposure to acid in very low birth weight infants presenting or not BDP. The symptoms attributable to gastroesophageal reflux are frequent in both groups: however, in very low birth weight infants, not presenting BPD, a clinical progression complicated by gastroesophageal reflux is less frequent. Nevertheless, BPD is associated with a higher frequency of gastroesophageal reflux treatment, the indication of any therapeutic modality must be cautious, and the laboratory investigation associated with a clinical evaluation may contribute to a reduction in the number of unnecessary treatment.

Keywords: Bronchopulmonary dysplasia; Gastroesophageal reflux; Apnea; Infant; Newborn

Abbreviations: LPS: Lipopolysaccharide; HI: Hypoxic Ischemia; SS: Sterile Saline; EPO: Erythropoietin; TNF-A: Tumor Necrosis Factor A; Hdacs: Histone Deacetylases; MBP: Myelin Basic Protein; MAP-2: Microtubule-Associated Protein-2; HDAC1mRNA: Histone Deacetylases-1 Mrna; PCR: Polymerized Chain Reaction; PVL: Periventricular Leukomalacia; PWM: Periventricular White Matter; WM: White Matter; Dnmts: Methyl transferase; Hats: Histone Deacetylases; SVZ: Subventricular Zone; DG: Dentate Gyrus

\section{Introduction}

Bronchopulmonary dysplasia (BPD) affects about $22 \%$ of very low birth weight (VLBW) newborns [1]. The disease has a turbulent clinical course, significantly contributing to morbidity and mortality in the neonatal period, and leaving long-term sequelae [2].

The frequency of Gastroesophageal Reflux (GER) causing symptoms and a complicated clinical course in premature infants presenting BPD during their stay in neonatal care units is not fully established [3-5] and widely questioned.

Although there is experimental and clinical evidence that sleep apnea occurs as a result of reflux episodes [6,7], the cause-effect relation between the conditions is controversial [8-10]. Similarly there is disagreement regarding the effects of GER in the pathogenesis and in BPD recovery $[5,11]$. The presence of pepsin in the tracheal aspirate in ventilated newborns during the first weeks of life, and the subsequent progression to BPD in these newborns may indicate the possibility of chronic aspiration as a mechanism in the genesis of BPD
[12]. Furthermore, there is evidence that symptoms associated with acid reflux episodes that reach or not the pharynx, if cleared slowly, are common in newborns presenting BPD on respiratory support $[13,14]$.

Despite the controversies, the presumptive diagnosis of GER has been quite frequent in neonatal units in North America, and there is indication that $24.8 \%$ of VLBW infants are treated for the condition [15]. Treatment is even more common (47.6\%) among VLBW infants who are discharged after 42 weeks of postmenstrual age, of which 75.7\% have DBP [15].

Given the uncertainty regarding the occurrence of GER in newborns presenting BPD and the frequency of GER treatment, the prospective study of distal esophagic $\mathrm{pH}$ monitoring (DEpHM) abnormalities in newborn infants presenting or not BPD was considered.

*Corresponding author: Maria Aparecida Mezzacappa, 101 Alexander Fleming St. Cidade Universitária Zeferino Vaz, PO Box: 6081,13083-881, Campinas, São Paulo, Brazil, Tel: +55 19 3521-9307; Fax +55 19 3521-9307; E-mail: mezacapa@uol.com.br, mezacapa@fcm.unicamp.br

Received December 14, 2013; Accepted February 14, 2014; Published February 16,2014

Citation: Mendes-Lopes T, Ribeiro JD, Mezzacappa MA (2014) High Prevalence of Esophageal Acid Exposure in Very Low Birth Weight Infants Presenting or Not Bronchopulmonary Dysplasia: A Prospective Cross-Sectional Study. J Neonatal Biol 3: 127. doi:10.4172/2167-0897.1000127

Copyright: (c) 2014 Mendes-Lopes T, et al. This is an open-access article distributed under the terms of the Creative Commons Attribution License, which permits unrestricted use, distribution, and reproduction in any medium, provided the original author and source are credited. 
Citation: Mendes-Lopes T, Ribeiro JD, Mezzacappa MA (2014) High Prevalence of Esophageal Acid Exposure in Very Low Birth Weight Infants Presenting or Not Bronchopulmonary Dysplasia: A Prospective Cross-Sectional Study. J Neonatal Biol 3: 127. doi:10.4172/21670897.1000127

Pge 2 of 5

The purpose of this study is to determine the prevalence of high acid exposure of esophagus, reflux index (RI) $\geq 10 \%$, in VLBW newborns presenting or not a diagnosis of $\mathrm{BPD}$, to establish the prevalence of signs/symptoms attributable to GER, and the treatment for both groups in a neonatal tertiary care unitof a university hospital. It was hypothesized that there is a higher frequency of DEpHM abnormalities, symptoms and clinical treatment in newborns diagnosed with BPD.

\section{Methods}

A prospective cross-sectional study was conducted. Newborn infants with birth weight $\leq 1500 \mathrm{~g}$ and with a diagnosis of BPD, according to the criteria of Bancalari et al. [16], born between April 2004 and December 2008 were included in the study. The comparison group included newborns of same weight and gestational age (24-32 weeks) who did not present respiratory failure in the first week of life, or who presented a short-term respiratory failure, and did not require oxygen therapy after the first week of life. In both groups, the subjects were included in the study after 28 days of life, with clinical stability, $100 \%$ enteral feeding and in a weight gain phase. The BPD group was included after being to at least one week of tracheal extubation.

The study protocol was conducted in accordance with the Declaration of Helsinki and approved by the Research Ethics Committee of the School of Medicine at University of Campinas (Unicamp), Brazil, and the families signed an informed consent document.

The criteria for exclusion used were malformations, genetic syndromes and chromosomal disorders, hypoxic-ischemic syndrome, structural anomalies in the central nervous system, grade IV periintraventricular hemorrhage (PIVH), periventricular leukomalacia and DEpHM with technical problems or lasting less than 18 hours, death, discharge, and transference prior to the exam date.

DEpHM was performed by researchers under standardized conditions. During the exam, the subjects stayed in the dorsal decubitus position and had pulse oximetry monitoring. The equipment used for $\mathrm{pH}$ registering was Digitrapper MKIII-Medtronic Synectics ${ }^{\oplus}$, Stockholm, Sweden. Technical calibration procedures and equipment installation were previously described [17]. The electrode was introducedup to the distance established by the arithmetical average of the length obtained by the $\mathrm{pH}$ turning point and location of the Lower Esophageal Sphincter (LES) determined by manometry [18]. A chest radiograph was taken to confirm the position of the electrode at the level of T6-T7 vertebral bodies.

During the exam, every four hours, the subjects received formula for premature newborns or fortified expressed breast milk, orally or via a gastric tube. The total enteral volume during recordings was set at $130-140 \mathrm{~mL} / \mathrm{k} /$ day. Prokinetic and antacid drugs were discontinued at least 48 hours before the exam. The use of xanthines (caffeine, aminophylline) was not contraindicated during the test.

PH measurements were taken every 4 seconds. Reflux episodes were defined as intraesophageal $\mathrm{pH}$ fall below 4 for at least 15 seconds. The maximum duration of each test was between 18-24 hours, and at the end of this period the records were using the Esop Hagram software (Gastrosoft Inc., MN, USA). DEpHM was considered abnormal when the total time with $\mathrm{pH}<4$ or reflux index (RI) was $\geq 10 \%$.

Information on the signs/symptoms of GER and concerning the treatment used during the stay in the neonatal hospital was obtained from the medical records. Symptomsthat werepresent before or after DEpHM were: apnea of prematurity non-responsive to xanthines, lateonset apnea coinciding with the end of the parenteral/enteral transition, apnea associated with milk in the mouth, apparent life-threatening events, repeated episodes of $\mathrm{SaO}_{2}<80 \%$, and frequent bradycardia, with or without need for supplemental oxygen, vomiting/regurgitation, unexplained worsening of pulmonary function, coughing, stridor, suspected pulmonary aspiration, irritability, back-arching. The descriptive variables studied were birth weight, gestational age [19], adequacy of weight for age,gender, neonatal respiratory disorder, use of xanthines, prenatal and postnatal corticosteroid use, oxygen therapy and gastric tube use duration, postmenstrual age and weight at examination, signs and symptoms suggestive of Gastroesophageal Reflux Disease (GERD), neurologic exam abnormalities (hypotonic syndrome, hypertonic syndrome, hyperexcitability syndrome, hemisyndrome or apathy syndrome), duration of hospital stay, GERD treatment.

The results of DEpHM remained confidential and held by the researchers. Results were only provided to the clinical team when requested, after GER was suspected based on clinical manifestations, according to the unit's code of conduct. Postural and dietary treatment, transpyloric/jejunal tube, pharmacologic, and surgical treatment were indicated by the staff. Treatment was introduced in the following sequence.

\section{Sample Size}

A sample size of 35 subjects was estimated by using a method of proportions calculation for a finite population using a prevalence average of $\mathrm{RI} \geq 10 \%$, obtained from previous data $(45.4 \%)[4,5]$ and the estimates of prevalence in the Service (41.7\%), accepting a difference of 5 to $10 \%$, with an alpha of 0.05 . The sample size of the comparison group who did not present BPD was established at 15.

\section{Data Analysis}

For the comparison between the groups, the Chi-square and Fisher's Exact tests were used for categorical variables. The Mann-Whitney test was used for numerical variables. The SAS System for Windows (Statistical Analysis System),version 9.1.3 from SAS Institute Inc, 20022003, Cary, NC, USA, was used. The significance level adopted was $5 \%$.

\section{Results}

Thirty-five (35) subjects presenting BPD and 15 subjects from the comparison group were studied. Forty-two (42) subjects with BPD were excluded for the following reasons: family refusal $(n=2)$, deaths $(n=7)$, central nervous system structural anomalies, and grade IV PIVH $(n=11)$, peri-intraventricularleukomalacia $(n=4)$, genetic syndrome $(n=2)$, digestive tract malformation and heart disease $(n=2)$, discharge and transfer prior to the test $(n=11)$, worsening of clinical condition during registers and technical problem in $\operatorname{DEpHM}(n=3)$.

In the comparison group, 50 newborns were excluded due to: technical problems in DEpHM $(n=3)$, family refusal $(n=4)$, leukomalacia $(n=1)$, colpocephalia $(n=4)$, genetic syndrome $(n=2)$, clinical suspicion of GER before obtaining the informed consent term $(n=10)$, death and poor clinical condition $(\mathrm{n}=3)$, transfer/discharge prior to $\mathrm{pH}$ registers $(n=23)$. All subjects tolerated the study procedures well without any concerns.

Subjects presenting BPD and the comparison group differed significantly in relation to birth weight and gestational age (Table 1). In the comparison group, 10 subjects had mild respiratory failure in the first week of life, 2 of them used mechanical ventilation (for 3 and 5 days), 8 remained in continuous pressure airway positive (CPAP) $(1.2$ \pm 0.7 days) (Table 1 ). 
Citation: Mendes-Lopes T, Ribeiro JD, Mezzacappa MA (2014) High Prevalence of Esophageal Acid Exposure in Very Low Birth Weight Infants Presenting or Not Bronchopulmonary Dysplasia: A Prospective Cross-Sectional Study. J Neonatal Biol 3: 127. doi:10.4172/21670897.1000127

Pge 3 of 5

\begin{tabular}{|c|c|c|c|}
\hline & $\begin{array}{l}\text { With BPD } \\
(n=35)\end{array}$ & $\begin{array}{l}\text { Without BPD } \\
(n=15)\end{array}$ & $\mathbf{P}$ \\
\hline BW (g) & $903.0 \pm 194.2$ & $1136.3 \pm 141.8$ & \multirow[t]{3}{*}{$0.0001^{*}$} \\
\hline Median & 875.0 & 1145.0 & \\
\hline P25-75 & 812.5-1012.5 & $1055.0-1190.0$ & \\
\hline GA (w) & $27.7 \pm 1.9$ & $29.7 \pm 1.5$ & \multirow[t]{3}{*}{$0.0006^{*}$} \\
\hline median & 27.0 & 30.0 & \\
\hline P25-75 & $26.5-29.0$ & $28.5-31.0$ & \\
\hline Male (n) & 18 & 9 & $0.5773^{\dagger}$ \\
\hline SGA (n) & 10 & 6 & $0.5142^{\ddagger}$ \\
\hline $\mathrm{RI} \geq 10 \%(\mathrm{n})$ & 23 & 14 & $0.0755^{\ddagger}$ \\
\hline Antenatal corticosteroid (n) & 20 & 11 & $0.2798^{\dagger}$ \\
\hline $\begin{array}{l}\text { Respiratory distress in the } \\
\text { first week of life }(n)\end{array}$ & 34 & 10 & -- \\
\hline Xanthine use (n) & 12 & 5 & $0.9481^{\dagger}$ \\
\hline $\begin{array}{l}\text { Duration of gastric tube } \\
\text { use (d) }\end{array}$ & $59.9 \pm 21.9$ & $34.4 \pm 3.7$ & \multirow[t]{3}{*}{$0.0001^{*}$} \\
\hline median & 57.0 & 33.0 & \\
\hline P25-75 & $47.0-69.0$ & $31.5-37.5$ & \\
\hline Postnatal corticosteroid (n) & 15 & 0 & $0.0019^{\ddagger}$ \\
\hline Weight at pH exam (g) & $1758.6 \pm 449.7$ & $1714.3 \pm 249.2$ & \multirow[t]{3}{*}{$0.8489^{*}$} \\
\hline median & 1650.0 & 1630.0 & \\
\hline P25-75 & $1505.0-2060.0$ & $1610.0-1892.5$ & \\
\hline $\begin{array}{l}\text { Postconceptional age at } \mathrm{pH} \\
\text { exam (w) }\end{array}$ & $36.1 \pm 3.6$ & $34.6 \pm 1.5$ & \multirow[t]{3}{*}{$0.1421^{*}$} \\
\hline median & 36.0 & 35.0 & \\
\hline P25-75 & $34.0-38.0$ & $33.0-36.0$ & \\
\hline Duration of hospital stay (d) & $100.8 \pm 40,7$ & $53.0 \pm 13.3$ & \multirow[t]{3}{*}{$0.0001^{*}$} \\
\hline median & 97.0 & 55.0 & \\
\hline P25-75 & $76.0-113.0$ & $41.0-62.0$ & \\
\hline $\begin{array}{l}\text { Abnormal neurological exam } \\
\text { at hospital discharge }(n)\end{array}$ & 28 & 8 & $0.0853^{\ddagger}$ \\
\hline Symptoms/signs of GER & 32 & 11 & $0.1764^{\ddagger}$ \\
\hline
\end{tabular}

\begin{tabular}{|l|c|c|c|c|c|}
\hline Signs/symptoms* & $\begin{array}{c}\text { With BPD } \\
(\mathbf{n = 3 5 )}\end{array}$ & $\begin{array}{c}\text { \% } \\
\text { Without } \\
\text { BPD } \\
(\mathbf{n = 1 5 )}\end{array}$ & \% & $\mathbf{p}$ \\
\hline Desaturations (n) & 26 & 81.3 & 5 & 33.3 & $0.015^{\dagger}$ \\
\hline Apnea (n) & 21 & 65.6 & 11 & 73.3 & $0.562^{\dagger}$ \\
\hline Bradycardia (n) & 9 & 28.1 & 1 & 6.7 & $0.245^{\dagger}$ \\
\hline Regurgitation, vomiting (n) & 10 & 28.6 & 5 & 33.3 & $0.746^{\dagger}$ \\
\hline $\begin{array}{l}\text { Suspicion of aspiration,irritabili } \\
\text { ty,stridor, coughing (n) }\end{array}$ & 7 & 20.0 & 1 & 6.7 & $0.407^{\dagger}$ \\
\hline Medical or surgical treatment (n) & 28 & 80.0 & 3 & 20.0 & $<0.001^{\dagger}$ \\
\hline
\end{tabular}

Values expressed asabsolute frequencyand percentage, BPD=Bronchopulmonary Dysplasia, $\mathrm{n}=$ number, ${ }^{\dagger}$ Chi-square test, ${ }^{*}$ more than one symptom/sign persubject. Table 2: Clinical manifestations attributable to GER and treatment indication $(n=50)$.

\begin{tabular}{|l|l|l|}
\hline Reflux index & $\begin{array}{l}\text { With symptoms and } \\
\text { signs }\end{array}$ & $\begin{array}{l}\text { Without symptoms and } \\
\text { signs }\end{array}$ \\
\hline $\mathrm{RI}<10 \%$ & $11(84.62 \%)$ & $2(15.38 \%)$ \\
\hline $\mathrm{RI} \geq 10 \%$ & $21(56.76 \%)$ & $16(43.24 \%)$ \\
\hline
\end{tabular}

Values expressed asabsolute frequencyand percentage, $n=$ number, RI=Reflux Index.

Table 3: Symptoms and signs suggestive of gastroesophageal reflux during the hospital stay $(n=50)$

\section{Discussion}

The present study demonstrates that the RI $\geq 10 \%$ prevalence was high and without significant difference in VLBW infants presenting or not BPD. The clinical signs attributable to GER were quite prevalent in both groups. During their stay in the neonatal unit, $80 \%$ of the subjects presenting BPD received anti-reflux treatment. The prevalence of high $\mathrm{RI}$ in newborns without BPD was unexpectedly high.

In this study, the isolated use of $\mathrm{pH}$ monitoring, not combined with esophageal intraluminal impedance, merits a discussion. In the last decade, combined esophageal impedance-pH monitoring is the most widely used method for the identification of acid and non-acid reflux $[8,10,13,14,20,21]$. However, this technology does not detect a substantial part of the acid events in premature infants [14,22]. Therefore, acid reflux identified only by $\mathrm{pH}$ monitoring ( $\mathrm{pH}$ only refluxes) has been associated with symptoms related to GERD [23], especially in BPD [14].

There is no consensus on the best cutoff point for RI, since reference values were never defined for a large sample of premature infants. We used $10 \%$ because it is the most commonly used value, although RI $>15 \%$ is also recommended [24].

A comparison between the results of different authors on the prevalence of abnormal findings of DepHM, and the prevalence of symptoms possibly associated with GER is difficult, since studies had non-matching diagnostic criteria, and different standardizations for the test. In newborn infants presenting BPD, RI $\geq 10 \%$ occurred in $36.4 \%$ of cases in a prospective study [5], and in $30 \%$ and $63 \%$ in retrospective studies [3,4]. Only one study compared the prevalence of RI $\geq 10 \%$ and clinical signs between newborns presenting or not BPD, and no differences between groups were obtained similarly to this study [3].

The frequency of high RI and the association with clinical signsmay depend on the diagnostic method used accuracy, as well as the technical conditions and test standardization, such as type and volume of milk, interval between feedings [9,23], and body positioning [25]. On the other hand, findings of high RI in premature infants with GER suggestive symptoms may be attributed, in part, to immaturity or impairment of digestive and respiratory functions [9]. Extrinsic and intrinsic controls 
Citation: Mendes-Lopes T, Ribeiro JD, Mezzacappa MA (2014) High Prevalence of Esophageal Acid Exposure in Very Low Birth Weight Infants Presenting or Not Bronchopulmonary Dysplasia: A Prospective Cross-Sectional Study. J Neonatal Biol 3: 127. doi:10.4172/21670897.1000127

of lower esophageal sphincter function, as well as the control of the respiratory center, are situated in the nucleus of the solitary tract, in the brainstem. Thus, in premature infants a high RI may coexist with apnea of prematurity, without any causal relation [26], an assumption that may explain the results obtained in this study.

Thus, the presence of high exposure of the esophageal mucosa to acid $\mathrm{pH}$ is not an isolated and unequivocal parameter for GER [14]. High RI values may also not have any significance, since the occurrence of complications depends on the duration of episodes and the intraesophageal level achieved by the reflux episodes, as well as the exacerbation of chemolaryngeal and intrinsic esophageal reflex responses. The latter response is the ultimate determinant of noxious events $[13,14,27]$.

Considering the recent evidence that $20-33 \%$ of apnea $[8,13]$ and $94.3 \%$ of other symptoms present in VLBW infants affected by BPD may have a temporal causal association with reflux episodes, it becomes evident that some newborns may benefit from therapeutic measures [14].

GER treatment in VLBW infants in the majority of American neonatal units is empirical, since $\mathrm{pH}$ monitoring isolated or combining esophageal impedance-pH monitoring is not routinely used [28]. In this study, it was observed that $65.6 \%$ of cases with DBP had RI $\geq 10 \%$. However, $80 \%$ total cases were treated, suggesting that the combination of clinical and laboratory criteria may contribute to reduce the treatment indication [29]. The indication of GER treatment in this study was high and consistent with that previously described [15], although it is impossible to state its adequacy, in view of all the existing uncertainty.

The inclusion criteria for the comparison group may be indicated as a limitation of this study. Ideally, premature infants who did not exhibit apnea/desaturation should have been studied. However, because of the gestational age established for study inclusion, these events occurred in most of these subjects. In addition, the low gestational age contributed to the presence of respiratory failure in the first week of life, which in turn is a risk factor for high RI [30,31]. Likewise, the minimum chronological age of 28 days, in order to standardize the postmenstrual age among groups [17], hindered the inclusion of healthy newborns in the group that did not present BPD, due to a shorter hospital stay.

For all these considerations, the comparison group apparently was not the ideal control. The electrical impedance results coupled to a $\mathrm{pH}$ electrode, in 21 newborns of 30-34 weeks of gestational age, healthy, with 9-17 days of life, where only $9.5 \%$ of the subjects had a RI higher than $10 \%$, corroborate this hypothesis.

\section{Conclusions}

The results obtained in this study allows us to conclude that the high prevalence of acid exposure and symptoms is not greater in premature infants presenting $\mathrm{BPD}$, encouraging a debate on the frequent indication of GERD treatment in this group, on the basis of either of the two isolated parameters [15]. Until unequivocal criteria, applicable to daily practice, are established, the introduction of antireflux therapy, especially pharmacological, must be prudent and preferentially based on the investigation of the intensity of esophageal acid exposure. Treatment should only be maintained in infants showing an evident response to the treatment, considering the possible adverse effects.

\section{Acknowledgements}

This study had the financial support of the Coordinating Training Center for Higher Education Personnel (CAPES), and the Research Support Foundation of the State of São Paulo (FAPESP) (Grant $n^{\circ}$ 03/07591-2). The authors would like to thank Mrs. Andréa Ferreira Semolini and Mrs. Cleide Moreira Silva for the statistical assistance, Mrs. Marise Mello CarnelossiBrunelli for her assistance with the esophageal $\mathrm{pH}$ monitoring data and Mariana Veras for the English revision. We also would like to thank all parents and health care providers at the Neonatology Sector who dedicated their time to this study.

\section{References}

1. Fanaroff AA Stoll BJ, Wright LL, Carlo WA NICHD Neonatal Research Network, et al. (2007) Trends in neonatal morbidity and mortality for very low birthweight infants. Am J Obstet Gynecol 196: 147.e1-8.

2. Bancalari E (2006) Bronchopulmonary dysplasia: old problem, new presentation. J Pediatr (Rio J) 82: 2-3.

3. Akinola E, Rosenkrantz TS, Pappagallo M, McKay K, Hussain N (2004) Gastroesophageal reflux in infants $<32$ weeks gestational age at birth: lack of relationship to chronic lung disease. Am J Perinatol 21: 57-62.

4. Shah S, Coughtrey H, Dawson J (2001) Gastroesophageal reflux and chronic lung disease: is there a relationship. J Perinatol Med 29.

5. Yeo KL (1998) Gastroesophageal reflux (GER) and chronic lung disease (CLD) in very low birthweight (VLBW) infants. Ped Res 43.

6. Herbst JJ, Minton SD, Book LS (1979) Gastroesophageal reflux causing respiratory distress and apnea in newborn infants. J Pediatr 95: 763-768.

7. Thach BT (1997) Reflux associated apnea in infants: evidence for a laryngea chemoreflex. Am J Med 103: 120S-124S.

8. Corvaglia L, Zama D, Gualdi S, Ferlini M, Aceti A, et al. (2009) Gastrooesophageal reflux increases the number of apnoeas in very preterm infants. Arch Dis Child Fetal Neonatal Ed 94: F188-F192.

9. Molloy EJ, Di Fiore JM, Martin RJ (2005) Does gastroesophageal reflux cause apnea in preterm infants? Biol Neonate 87: 254-261.

10. Peter CS, Sprodowski N, Bohnhorst B, Silny J, Poets CF (2002) Gastroesophageal reflux and apnea of prematurity: no temporal relationship. Pediatrics 109: 8-11.

11. Sindel BD, Maisels MJ, Ballantine TV (1989) Gastroesophageal reflux to the proximal esophagus in infants with bronchopulmonary dysplasia. Am J Dis Child 143: 1103-1106.

12. Farhath S, He Z, Nakhla T, Saslow J, Soundar S, et al. (2008) Pepsin, a marker of gastric contents, is increased in tracheal aspirates from preterm infants who develop bronchopulmonary dysplasia. Pediatrics 121: 253-259.

13. Jadcherla SR, Gupta A, Fernandez S, Nelin LD, Castile R, et al. (2008) Spatiotemporal characteristics of acid refluxate and relationship to symptoms in premature and term infants with chronic lung disease. Am J Gastroentero 103: $720-728$

14. Jadcherla SR, Peng J, Chan CY, Moore R, Wei L, et al. (2011) Significance of gastroesophagealrefluxate in relation to physical, chemical, and spatiotempora characteristics in symptomatic intensive care unit neonates. Pediatr Res 70 : 192-198.

15. Malcolm WF, Gantz M, Martin RJ, Goldstein RF, Goldberg RN, et al. (2008) Use of medications for gastroesophageal reflux at discharge among extremely low birth weight infants. Pediatrics 121: 22-27.

16. Bancalari E, Abdenour GE, Feller R, Gannon J (1979) Bronchopulmonary dysplasia: clinical presentation. J Pediatr 95: 819-823.

17. Mendes TB, Mezzacappa MA, Toro AA, Ribeiro JD (2008) Risk factors for gastroesophageal reflux disease in very low birth weight infants with bronchopulmonary dysplasia. J Pediatr (Rio J) 84: 154-159.

18. Omari TI, Benninga MA, Haslam RR, Barnett CP, Davidson GP, et al. (1999) Lower esophageal sphincter position in premature infants cannot be correctly estimated with current formulas. J Pediatr 135: 522-525.

19. Ballard JL, Khoury JC, Wedig K, Wang L, Eilers-Walsman BL, et al. (1991) New Ballard Score, expanded to include extremely premature infants. J Pediatr 119: 417-423.

20. Corvaglia L, Mariani E, Aceti A, Capretti MG, Ancora G, et al. (2009) Combined oesophageal impedance-pH monitoring in preterm newborn: comparison of two options for layout analysis. Neurogastroenterol Motil 21: 1027-1027e81.

21. López-Alonso M, Moya MJ, Cabo JA, Ribas J, Macias MC, et al. (2006) Twenty-for-hour esophageal impedance-pH monitoring in healthy preterm 
Citation: Mendes-Lopes T, Ribeiro JD, Mezzacappa MA (2014) High Prevalence of Esophageal Acid Exposure in Very Low Birth Weight Infants Presenting or Not Bronchopulmonary Dysplasia: A Prospective Cross-Sectional Study. J Neonatal Biol 3: 127. doi:10.4172/21670897.1000127

Pge 5 of 5

neonates: rate and characteristics of acid, weakly acidic, and weakly alkaline gastroesophageal reflux. Pediatrics 118: e299-308.

22. Di Fiore JM, Arko M, Churbock K, Hibbs AM, Martin RJ (2009) Technical limitations in detection of gastroesophageal reflux in neonates. J Pediatr Gastroenterol Nutr 49: 177-182.

23. Omari TI, Barnett CP, Benninga MA, Lontis R, Goodchild L, et al. (2002) Mechanisms of gastro-oesophageal reflux in preterm and term infants with reflux disease. Gut 51: 475-479.

24. Davidson G (2003) The role of lower esophageal sphincter function and dysmotility in gastroesophageal reflux in premature infants and in the first year of life. J Pediatr Gastroenterol Nutr 37 Suppl 1: S17-S22.

25. Ewer AK, James ME, Tobin JM (1999) Prone and left lateral positioning reduce gastro-oesophageal reflux in preterm infants. Arch Dis Child Fetal Neonatal Ed 81: F201-F205.
26. Amin RS (2000) Gastroesophageal reflux and infant apnea. J Pediatr 137: 298300

27. Slocum C, Hibbs AM, Martin RJ, Orenstein SR (2007) Infant apnea and gastroesophageal reflux: a critical review and framework for further investigation. Curr Gastroenterol Rep 9: 219-224.

28. Ward RM, Lemons JA, Molteni RA (1999) Cisapride: a survey of the frequency of use and adverse events in premature newborns. Pediatrics 103: 469-472.

29. Birch JL, Newell SJ (2009) Gastrooesophageal reflux disease in preterm infants: current management and diagnostic dilemmas. Arch Dis Child Fetal Neonatal Ed 94: F379-F383.

30. Khalaf MN, Porat R, Brodsky NL, Bhandari V (2001) Clinical correlations in infants in the neonatal intensive care unit with varying severity of gastroesophageal reflux. J Pediatr Gastroenterol Nutr 32: 45-49.

31. Mezzacappa MA, Rosa AC (2008) Clinical predictors of abnormal esophageal $\mathrm{pH}$ monitoring in preterm infants. Arq Gastroenterol 45: 234-238. 